\title{
Juan Sebastián Bach, visto desde nuestro siglo
}

Ningún camino más certero y penetrante que el del arte, para auscultar la significación profunda de una época. La calificación de sus grandes artistas es la calificación de las grandes corrientes espirituales que le dieron vida. Unas veces es el caso del artista revolucionario cuyo mensaje denuncia una verdad oculta todavía a la comprensión del hombre medio de su tiempo; otras es el del artista en quien se sintetiza y culmina un período; unas veces es el artista que anuncia una etapa, otras, el artista quella agota. de Letras

Por eso, en el arduo momento que vive nuestra cultura en estos años, al hacer crisis el cillo histórico iniciado con el Renacimiento y la Reforma, asume renovado interés el meditar sobre lo que representaron sus grandes artistas, uno de los cuales -entre los más geniales y profundos- fué Juan Sebastián Bach. No precisa para esto detenerse, una vez más, en los datos pormenorizados de una biografía o en la enumeración y análisis de cada una de sus obras, tantas veces repetidos. Importa, en cambio, esclarecer nuestra propia visión, desde este momento histórico que nos ha tocado vivir, para formular un juicio actual, sustentando en la comprensión que hoy vamos alcanzando de lo que significó el rumbo seguido por nuestra cultura en los últimos siglos.

El primer carácter que se manifieste en la obra de Bach, es e? de la culminación de una manera de ser del arte $y$, por tanto, del espíritu. Schweitzer, uno de los que más penetrantemente la ha estudiado, decía: "Bach es un final, un término. Nada parte de él, todo conduce a él. Escribir la verdadera biografía de este maestro, significaría historiar la vida y el desārrollo del arte alemán que en él culmina y se agota; comprendiéndolo al mismo tiempo en sus tendencias y en sus erro- 
res". La generación siguiente - la de sus propios hijos, notables músicos - pertenece a otro mundo, Juān Cristián, el menor de ellos, llarra frecuentemente a su padre "vieja peluca" para significar que pertenecía a un arte y una mentalidad ya superados.

Por esto, la genialiad de Bach no fué comprendida por sus contemporáneos, pero no porque fuese el revolucionario que hablaba un idioma nuevo, sino porque, ya desde sus propios hijos, habían dejado de entender el hondo significado de la vieja lengua polifónica, que hundía sus raíces en los siglos medioevales, y que supervivía, prodigiosamente, en la obra del anciano maestro. Cuatro años después de su muerte, publica un diario de Leipzig la enumeración de los diez mejores compositores alemanes y el nombre de Bach, entre los de otros músicos hoy olvidados, figura únicamente en sétimo lugar.

Se admira en él solo al "virtucso" del órgano y en sus obras, apenas al habilísimo urdidor de complicadas tramas contrapuntísticas. En un juicio aparecido en 1737 — todavía en yida de Bach - dice Juan Adolfo Scheibe (citado por Erwin Leuchter en su obra sobre el compositor): "Este gran hombre podría despertar la admiración de naciones enteras si poseyera más placidez y si no privara a sus obras de lo natural, por su carácter ampuloso y confuso y no ensombreciera su belleza con excesivo artificio. Pretende que todas las voces subsistan juntas y con idéntico peso, de modo quje no sen feconozça entre ellas ninguna principal. La ampulosidac lo ha hecho caer de to natural a lo artificioso, de lo sublime a lo oscufo; $y$ solo senamira en eir su laborioso trabajo y su extraordinario afán, gastado en vano, por desgracia, pues contradice la Razón".

Es singularmente ilustrativa también, sobre este punto, la apreciación de Charles Nef, en su Historia de la Música: "El mundo musical de su tiempo - dice --, encadenado por los suaves acentos de la escuela napolitana (de ópera) no le prestó atención y no comprendió su genio". Bach, en efecto, no ejercitó casi ninguna influencia entre sus contemporáneos y sus obras - salvo el "Clavo bien Templado" y algunos motetes - quedaron inéditas, escritas de su propia mano y muchas están perdidas hoy. Unicamente un siglo más tarde, como todos sabemos, Mendelssohn vendrá a revelar al mundo la genial "Pasión según San Mateo", que en el tiempo de su creación había sido ejecutada sćlo una o dos veces, y el nombre de Juan Sebastián Bach, se impondrá definitivamente con la autoridad y el valor que no pudieron descubrir los que vivieron demasiado cerca de él. 
¿Y cuál es la explicación de este destino adverso al genio de Bach? ¿Cuál es la razón profunda de que sus contemporáneos no entendieran ya su sublime lenguaje?. Creo que en la respuesta a estas preguntas podemos precisar algo de lo más esencial de su significación histórica, que los hombres de hoy podemos ver con inusitada claridad.

Si reducimos el panorama de la cultura occidental en el momento decisivo del Renacimiento y la Reofrma, a sus mínimos términos esquemáticos podríamos desentrañar de su compleja trama de aspiraciones, ideas y acontecimientos, dos fenómenos esenciales: El primero, es el quebrantamiento de la concepción teocéntrica de la vida, en que la idea de Dios penetraba todos los pensamientos y actividades del hombre, y el advenimiento de la concepción antropocéntrica, que erigió al hombre en punto de gravitación de toda la cultura, y que había de darle un nuevo ángulo de mira, cada vez más exclusivamente temporal y terreno, para contemplar y comprender el Universo. Tal transformacićn ha de traducirse, para el valor estético, en la suplantación de un gran arte de sentido fundamentalmente religioso - el arte medioeval - por un arte cada vez más definidamente profano y laico - el del Renacimiento hasta nuestros días -

El segundo fenómeno, profundamente vinculado al anterior, fué el quebrantamiento de una estructura y sobre todo una mentalidad de índole social y jerárquica, que realizó la Cristiandad medioeval, y el advenimiento de una thspiración cadal vez̄ más decididamente individualista, que realiza el Renacimiento y que la Reforma traspone al campo religioso; desvinculando al creyente de una auforidad ecuménica y afirmando el libre examen, que conducirá a la multiplicación de sectas. En el dominio del arte, asimismo, contra la expresión eminentemente objetiva y colectivista de la Edad Media, reaccionará un arte que, cada vez más claramente, en los tiempos modernos se tornará expresión de vida y sentimientos personales.

La música es probablemente el campo estético en el que esta transformación del mundo va a operar su más significativa experiencia. Pero también la más tardía. Y la razón de esto último es que ese arte está elaborando entonces, por primera vez, algunos de sus esenciales elementos, como la estructuración armónica y la concepción específica instrumental. Por eso, el siglo XVII, que encuentra ya un nuevo arte plástico, florecido desde dos centurias antes, de acuerdo con la mentalidad y el credo renacentista, es para la música un siglo de búsquedas y hallazgos trascendentales en el que germinan, lentamente, las nuevas formas y se abren insospechadas posibilidades. 
En el dominio de la música vocal, el gran arte profano de.los tiempos modernos va a dar, como expresión individualista, en oposición a la inspiración eminentemente coral de la Edad Media, el solo de canto. Este se abrirá camino, sobre todo, en el desarrollo triunfal y avasallador de la ópera, nacida en Italia, como tantos otros exponentes anteriores del Renacimiento, y que inunda a toda Europa como el genuino espectáculo del espíritu fastuoso y cortesano del absolutismo barroco.

En el dominio de la música instrumental la evolurión va a ser mucho más lenta y sólo madurará a mediados del siglo XVIII con la irea ción del estiło llamado "homófono", en el que predomina una melodía principai en oposición al contrapuntístico de melodías múltiples de iqual importancia, que suenan simultáneamente. En el estilo homófono, que cultivan ya los hijos de Bach y culmina en Haydn, Mozart y Beethoven, es posible, como en el solo de canto, la "expresión" subjetiva e mtima que no puede dar el contrapunto, y que reclamaba ya, con la denominación de "lo natural", Juan Adollo Scheibe, el crítico de 1737 que homos citado antes, en oposición a la objetividad, que llamaba "lo artificial", de la polifonía.

En la plenitud del florecimiento operístico, brillante y mundano, de principios del siglo XVIII y ante las fascinadoras promesas expresivistas del nuevo estilo instrumentah Juan Sebastián Bach, músico medularmente religioso que se expresa. en el estilo impersonal del contrapunto, ha-

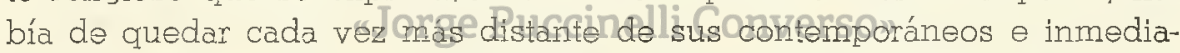
tos sucesores, como el genio solitario de un mundo ya olvidado. No pudo ser de otro modo. "Bach — dice Leuchter - hijo carnal del espíritu eclesiástico, cuya obra suprapersonal estaba enteramente al servicio de la Iglesia, debía ser extraño a una época que proclamaba lo 'humano" y 'lo subjetivo". En otro lugar de su libro sobre este músico agrega: "Bach es el más perfecto representante del tipo de artista obietivo". Y Schweitzer, incidiendo en el mismo rasgo esencial, afirma: "Este genio no es individual, sino que más allá de este límite totaliza a.go supraindividual, siglos enteros, generaciones enteras han trabajado en la obra ante cuya magnitud nos detenemos con veneración".

Por esto, por más que como hombre del siglo XVIII conoce la irera y sabemos que algunas veces decía a Friedemann, su hijo mayor, vamos "para oir esos lindos cantos de teatro", jamás se le ocurrió componer ćperas, y su escritura para las voces quedó ajena normalmente al estilo propiamente vocal y dramático para permanecer en gran medida instrumental. 
Igualmente, en medio del arrollador avance del arte profano que había dejado atrás, definitivamente, todo gran florecimiento de arte religioso, Juan Sebastián Bach, era, por excelencia, un músico religioso. Y lo era en mérito de la razón que había dado impulso a las grandes $\epsilon$ pocas de ese arte: la hondura de una vida auténticamente teocéntrica. A este respecto son preciosas las citas que pueden extraerse a cada pasc de la deliciosa "Pequeña Crónica" atribuída a Ana Magd:alena Bach, la segunda esposa del maestro, quien relata con amorosa pro.ijidaj su admirable vida íntima. "Parecerá extraño — dice- si se considera el gran número de pastores luteranos que he conocido, consagrados a dar buenos ejemplos, a pornunciar sermones piadosos y a enseñar los caminos del Señor, pero Sebastián no se les parecía: en él la religión permanecía oculta, pero siempre viva y presente". Y más adelante agrega: "En el fondo de su grande alma estaba siempre la imagen del Crucificado y su más alta música lanza el grito de amor y el deseo de la muerte que le inspiraba la visión de Cristo en el Calvario".

En todo momento, nos revela en su esposo, Ana Magdalena, una visión distinta y superior de la vida a la fincada en puros valores hunos. 'Aceptaba - dice - el entusiasmo de sus oyentes como un tributo a su profesión de músico, pero nunca le ví orgulloso de sus triunfos, ni tampoco turbado por el mal éxito. Sentíase que alentaba en él otro ideal". "Al final de susp partituras, Sebastián escribía invariablemente: S. D. G. o sea "soll Dei gloriam", toda la gloria para Dios'.

Ciertamente, podríaños decit quleien cell sigils XVIII la música religiosa, por última vez, con Juan Sebastián Bach, es oración; y obra de arte sólo "por añadidura", como lo fué la de Palestrina, Vitoria y la de tantos polifonistas medioevales o la de los anónimos creadores del canto gregoriano, quienes sin un especial propósito estético elevaron imperecederos monumentos a la Belleza. Después de Bach, con raras excepciones, la música religiosa es el fruto de un propósito estético, que las más veces no resulta oración ni "por añadidura".

Los rasgos más hondos de la personlidad de Bach definen a este artista genial de la música protestante, más allá de lo que él mismo habría podido sospechar, como un cabal exponente de la Cristiandad medioeval, que el protestantismo quebrantó en el siglo XVI. Su profunda y ejemplar religiosidad, que adiniere sincerísimamente al credo luterano, responde, sin embargo, a una mentalidad ajena a la inspiración individualista aportada por su religión. Bach es todavía, en gran parte, un hombre de la Edad Media , con una visión y emoción del mundo profundamente religiosa, colectivista y jerárquica. Así nos lo revela su 
obra, en la que figura, al lado y a semejante altura de la "Pasión según San Mateo", la "Gran Misa católica en Si bemol", compuesta para la. Corte de Dresde.

Hoy, en que se afirma en las corrientes del pensamiento occidental un resurgimiento espiritualista y trascendente, a la vez que una tendencia definitivamente colectivista y orgánica en la concepción de lo social, la personalidad de Juan Sebastián Bach, asume - más allá de su pura convicción ideológica y, sin saberlo, en paradójica posición ante ella un valor de símbolo, cuyo significado se hace manifiesto con meridiana claridad.

César Arróspide de la Flor.

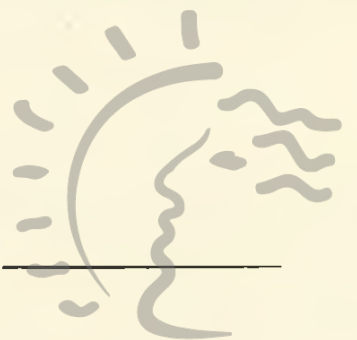

